\title{
Performance, working capital management, and the liability of smallness: A
}

\section{question of opportunity costs?}

\section{Vivien Lefebvre}

This paper studies the relationship between working capital management and firm operating performance and focuses on the moderating effect of size. We use a large sample of 56,221 small, medium, and large firms from France, Germany, and Italy and our results indicate that the impact of working capital management on performance strongly depends on size. We identify a higher sensitivity of performance to underinvestment in net operating working capital for small firms but no higher sensitivity to overinvestment. These findings suggest that small firms experience high opportunity costs from lost sales when their net operating working capital is low. Financial constraints and lack of financial management are discussed as potential explanations because both are expressions of the liability of smallness.

\section{Introduction}

The performance and survival of firms largely depends on the manager's ability to acquire, create and manage resources (Penrose 1959). Among them, financial resources, internal organization and strong reputation to attract customers are some of the most important ones or, at least, are so perceived by managers (Stinchcombe 1965; Aldrich and Auster 1986; Dodge et al. 1994). The literature commonly refers to the liability of smallness to describe the fact that small firms only have a limited amount of resources and difficult access to new ones. As a result, they face a higher rate of failure or bankruptcy and lower operating performances than larger firms. Working capital management (WCM) is, we suggest, one dimension of this liability. 
WCM refers to a firm's ability to identify and finance an efficient level of investment in the fraction of inventories and accounts receivable that is not covered by accounts payable. Intuitively, firms should maintain a low level of investment in these components to minimize both the interest expenses required to finance them and the storage costs of inventories. However, there are also benefits to a higher level of investment in WCM components. For example, small firms alleviate lack of reputation by increasing payment delays to suppliers which can result in additional sales (Wilson and Summers 2002). Thus, there is an optimal level of investment in WCM that balances these costs and benefits and maximizes firm's performance and value (Baños-Caballero et al. 2012, 2014; Aktas et al. 2015). Consistent empirical findings in the literature confirm that the relationship between performance and WCM is concave. However, no previous paper has investigated whether and to what extent this relationship is influenced by firm size.

Filling this gap appears important for several reasons. First, as small firms strongly rely on internally generated cash, the role of WCM is likely to be more important for them because it conditions the speed at which cash is available (Berger and Udell 1998; Cassar 2004). Larger firms on the other side have easier access to external funding and have therefore more flexibility in WCM, meaning they can more easily and at a lower cost finance a higher investment in WCM components (Kieschnick et al. 2013). Second, financial management is rather poor among small firms so despite their importance, WCM practices are often deficient for these firms (Peel and Wilson 1996; Peel et al. 2001; Howorth and Westhead 2003). For example, lack of WCM monitoring implies that small firms adjust WCM slower than larger firms making the effect of an inadequate level of WCM on performance more damaging. Thus, identifying the extent to which small firms' performance is affected by WCM is of significant interest for small firms' managers who lack time, skills and cash to dedicate to WCM (Peel and Wilson 1996). 
In this paper, we show that the performance of small firms is more sensitive to underinvestment in WCM components than the one of large firms, a finding we interpret as an expression of the liability of smallness. Small firms do not adjust investment in WCM either because they are driven by the need for internally generated cash or because they do not monitor WCM often enough. Both cases result in significant opportunity cost due to lost sales. Strikingly, we observe no conclusive difference between small, medium and large firms when it comes to overinvestment in the operating components of working capital. This suggests that small firms adjust faster investment in this latter case because they observe the costs of overinvestment.

Our work contributes to the literature in several ways. First, we extend the financial management literature as we investigate the role of size in the WCM-performance relationship. Second and unlike previous studies, we find that after controlling for endogeneity between performance and WCM, only underinvestment in WCM components impacts the performance of small and medium firms. Last, we show that the impact of underinvestment in WCM components on performance is higher for small firms than for medium or large firms.

The rest of the paper is organized as follows. First, we review the literature on the relationship between firm performance and WCM and develop our hypotheses in the particular case of small firms. Next, we present our sample and methodology and describe our results. We also perform several robustness tests and control for reverse causality. Last, we discuss our findings and potential implications of our work for managers, policy makers and research and present our conclusions.

\section{Theoretical foundations and hypotheses development}




\section{Working capital management and firm performance}

Firms need to purchase raw materials to produce finished goods and eventually sell them which results in accounts receivables and, depending on payment delays, cash. As the time it takes to produce, sell and cash-in is longer than the payment delays granted by suppliers, firms invest money in inventories and accounts receivables that remains locked up. This amount of cash, which is the fraction of working capital not covered by accounts payable, is referred to as net operating working capital (NOWC) (Hill et al. 2010). When the NOWC is positive, it means that firms need to finance this requirement which is mostly achieved through banking debt (Kieschnick et al. 2013). Therefore, firms seek to keep the NOWC as low as possible because the higher it is, the higher the amount of financial expenses the firm has to pay (Hill et al. 2010). If the NOWC is negative, it means that the firm generates available cash through its day-to-day operations, a situation that is generally considered as favorable.

The agility with which a firm adjusts the level of NOWC to internal and external conditions is called WCM. WCM represents an important part of financial management because it conditions the availability of internally generated cash or, in other words, the speed at which cash flows in. When a company grows and sales increase, the amount of NOWC grows as a mechanical result of an increase in inventories and accounts receivable.Thus additional financing is required. A stylized fact in the WCM literature is that firms largely overinvest in NOWC (Deloof 2003; Aktas et al. 2015). As a result, huge amounts of cash are unnecessarily locked up in inventories and accounts receivable, suggesting that most firms could improve their WCM by reducing investment in $\mathrm{NOWC}^{1}$.

\footnotetext{
${ }^{1}$ As noted by Aktas et al. (2015), longitudinal observations of WCM shows that the adoption of just-in-time practices in the last twenty years reduced the amount firms invest in inventories and, thus, in NOWC.
} 
When it comes to WCM, firms adopt two approaches (Hill et al. 2010). The "aggressive" approach consists in cutting investment in NOWC by reducing the levels of inventories and by asking customers to pay faster. Thus, the NOWC is smaller which means that less cash is tied up in the operating cycle. Costs induced by the financing of the NOWC are lowered which should, in turn, increase profitability. However, there are drawbacks to this aggressive WCM because low levels of inventories increase the risk of stock-outs. As stressed by Corsten and Gruen (2003), when customers face stock-outs they just go somewhere else to find the products they want and sales are lost for the firm. Additionally, the risk of an interruption in the production process is also increased when firms maintain low levels of inventories. These opportunity costs negatively affect firm's profitability suggesting that the relationship between firm profitability and investment in NOWC is not linear.

The "conservative" approach is the opposite of the aggressive approach. It means that firms grant longer payment delays and keep high level of inventories because they expect specific benefits. The risk of stock-outs is for example lower for a conservative WCM and it gives time to customers to assess product quality which in turn reduces information asymmetry between suppliers and customers (Blinder and Maccini 1991; Long et al. 1993; Ng et al. 1999). Granting longer payment delays to customers is also a way to gain and build trust with new clients (Summers and Wilson 2002). Customers may also select a supplier because it grants longer payment delays if no other criterion is available to differentiate between different suppliers (Shipley and Davis 1991). These expected benefits should positively affect firm's profitability as they represent potential gain in sales. The drawback of the conservative strategy is that it increases the amount of inventory and receivables and, thus, the need for finance. As we already stress, as firms use banking debt to finance NOWC, a conservative WCM brings additional financial expenses (Kieschnick et al. 2013). Storage costs, as well as related costs 
like insurance and security expenses, also increase as a result of a conservative WCM (Kim and Chung 1990).

Overall, both WCM approaches have benefits and drawbacks that impact firm performances, making the investigation of the role of WCM on firm performance the major research stream in the WCM literature. This literature reports consistent findings about the fact that the relationship between WCM and firm performance has an inverted-U shape as suggested by the previous arguments. In other words, there is an optimal level of investment in NOWC that balances the benefits and costs of WCM strategies (Baños-Caballero et al. 2012, 2014; Aktas et al. 2015; Ben-Nasr 2016).

The WCM literature considers both aggressive and conservative WCM as "strategies" (Hill et al. 2010). Therefore, it looks like an implicit assumption that firms target a NOWC level that best suits their current strategy, and that they try to achieve this level as soon as possible (Baños-Caballero et al. 2010). While this assumption is plausible for firms that have access to a large amount of resources, it appears less realistic for small firms which are known to have limited access to resources, especially financial ones. It is indeed possible that small firms deliberately constrain investment in NOWC to finance other fixed assets investments and operating expenses. Moreover, because small firms lack financial management, as we develop in the next section, it is likely that a fraction of them has no concrete WCM practices or a "passive" WCM (Khoury et al. 1999). This makes the investigation of the moderating role of size in the WCM-performance relationship an important issue that has not been previously addressed by the literature. Indeed, most of the recent works in the WCM literature only consider large or listed firms (Deloof 2003; Kieschnick et al. 2013; Baños-Caballero et al. 2014; Aktas et al. 2015; Ben-Nasr 2016). While Ebben and Johnson (2011) and Baños-Caballero et al. (2012) use samples of SMEs in WCM studies, it was not their purpose to compare large 
firms with small firms. Thus, we want to investigate the following research question: to what extent does size influence the NOWC-performance relationship?

\section{Small firms and working capital management}

For firms, the acquisition of resources is one of the keys to growth (Penrose 1959). A manager's ability to identify and acquire those resources is therefore a central aspect of firm growth. The combination of newly acquired resources with the ones the firm already has conditions the achievement of performance (Wernerfelt 1984; Barney 1991). Scarcity of internal resources and difficult access to external resources are obviously some of the biggest weaknesses small firms face, a concept that is commonly referred to as the liability of smallness (Aldrich and Auster 1986). Among them, lack of reputation and bargaining power (Stinchcombe 1965; Wilson and Summers 2002; Crook and Combs 2007), poor internal organization and management (Dodge et al. 1994) and constrained access to external finance (Cassar 2004) appear to be those with the strongest impact on WCM.

The lack of external financial resources is one of the major constraints that small firms have to face. Berger and Udell (1998) provide a theoretical explanation to these constraints based on information asymmetry. As small firms are informationally opaque, external investors are reluctant to provide them with cash because such an investment is riskier than in the case of a larger firm that has more collateral and a longer accounting track record. This reduces the amount of external finance small firms can access and increases the cost of these funds (Stiglitz and Weiss 1983; Audretsch and Elston 1997; Berger and Udell 1998; Cassar 2004). As a result, small firms need alternative sources of finance to grow in the early stages. A manager's ability to acquire financial resources and configure them to create value, which is financial management, is thus a key factor of survival and performance (Penrose 1959; Brinckmann et 
al. 2011). Brinckmann et al. (2011) distinguish between several aspects of financial management, like external financing and financing through operations. They show that, while most of the literature on small firms finance focuses on external financing, the role of financing through operations is even more crucial for small firms to grow. In other words, firms that generate cash internally alleviate limitations in the access to external finance. The bootstrapping literature offers several examples of techniques that start-ups' managers implement to generate cash internally. For example, such firms offer customers discounts on upfront payments and delay payment to suppliers (Winborg and Landström 2001). These practices have direct implications on WCM because they reduce the investment in NOWC as accounts receivable are lower and accounts payable are higher. Bootstrapping firms keep their NOWC as low as possible because they need to release cash quickly to finance operating expenses or investment. This means that, because of their resource constraint, small firms use what we describe as aggressive WCM to generate available cash. Because small firms may not have any other financing source, we expect them to maintain a low level of investment in NOWC even if this increases the risk of stock-outs and possible opportunity $\operatorname{costs}^{2}$. Therefore, the potential negative impact of an aggressive WCM on performance is expected to be higher for small firms because they cannot easily adjust investment in NOWC.

A modest but consistent stream of research shows that small firms struggle with $\mathrm{WCM}^{3}$ and that this contributes to explain a significant portion of small firms' failures (Berryman 1983). Survey based studies by Peel and Wilson (1996), Khoury et al. (1999) and Peel et al. (2001) show that financial management is rather poor among small firms. For example, the use

\footnotetext{
${ }^{2}$ We acknowledge that small firms' managers sometimes have external financing aversion and that they prefer internal financing, even if this constrains their firm's growth as suggested by Howorth (2001). This, however, does not impact our reasoning as the consequence of external financing aversion is that investment in NOWC is low as the need for internally generated cash is high. The impact of NOWC on firm performance is therefore the same whether a small firm is constrained by external factors or by internal preferences.

${ }^{3}$ Arend and Wisner (2005) show that small firms performance is negatively related with supply-chain management.
} 
of capital budgeting techniques to assess investment profitability is very low when compared to larger firms' standards (see for example Graham and Harvey 2001). In the case of WCM, small firms lack efficient practices in the management of the components of NOWC. This is particularly true for inventory management as more than a third of surveyed firms indicate that they never review inventory levels, turnover or re-order levels (Peel and Wilson, 1996; Howorth and Westhead 2003). Additionally, small firms' managers report that they review their WCM practices "whenever necessary" and not on a regular basis (Khoury et al. 1999). In the same vein, Howorth and Westhead (2003) show that small firms' WCM is based on routines. As small firms' managers have only limited resources to dedicate to WCM, both in terms of time and cash, they only focus on specific aspects of WCM for which they expect important returns. In other words, small firms' managers invest time in WCM when they need to release internally generated cash faster. Ebben and Johnson (2011) study a sample of US small firms and show that small firms' managers are more reactive than proactive when it comes to WCM, suggesting hereby a lack of WCM monitoring. This means that if small firms implement, deliberately or not, an inefficient level of investment in NOWC, they will realize and adjust it slower than larger firms. Thus, the impact of NOWC on smaller firms performance is likely to be higher than for larger firms.

Hypothesis 1: The performance of smaller firms is more sensitive to underinvestment in NOWC than the one of larger firms.

H1a: The performance of small firms is more sensitive to underinvestment in NOWC that the one of medium firms.

H1b: The performance of small firms is more sensitive to underinvestment in NOWC than the one of large firms. 
H1c: The performance of medium firms is more sensitive to underinvestment in NOWC than the one of large firms.

While the previous arguments indicate that smaller firms' performance should be more sensitive to underinvestment in NOWC, we also expect it to be more sensitive to overinvestment. Indeed, external financing costs are higher for smaller firms so financing investment in NOWC is more costly for them than for larger firms (Berger and Udell 1998, Cassar 2004). Using the same argument, storage costs are also higher for smaller firms. The financing costs of NOWC are overall higher for smaller firms than for larger which means that their impact on performance is expected to be higher than in the case of large firms. Last, the lack of WCM monitoring we describe previously is also likely to apply. This means that smaller firms will not quickly enough realize that their investment in NOWC is too high regarding a change in their operating conditions because they don't review their WCM practices often enough. We expect therefore the performance of smaller firms to be more sensitive to overinvestment in NOWC than the performance of larger firms.

Hypothesis2: The performance of smaller firms is more sensitive to overinvestment in NOWC than the one of larger firms.

$\mathrm{H} 2 \mathrm{a}$ : The performance of small firms is more sensitive to overinvestment in NOWC that the one of medium firms.

$\mathrm{H} 2 \mathrm{~b}$ : The performance of small firms is more sensitive to overinvestment in NOWC than the one of large firms.

$\mathrm{H} 2 \mathrm{c}$ : The performance of medium firms is more sensitive to overinvestment in NOWC than the one of large firms. 


\section{Methods}

\section{Sample}

To test our hypotheses, we use a sample of European firms. We use Bureau Van Dijk's Amadeus database to collect our data. This database provides access to financial and accounting information for private and public European firms. We include all German, French and Italian firms for which ten years of data are available which considerably reduces the number of firms for which we have information ${ }^{4}$. The observation period covers the years 2009 to 2018 . The choice of these countries is motivated by the fact that they are all bank-oriented economies which is important to capture the impact of the financing costs of WCM. Moreover, these countries have different practices about payment delays ${ }^{5}$ so we alleviate concerns that our results might be driven by a country's specific trade credit practices. The initial sample included 62,014 firms and we exclude financial and administration firms which is a common practice in the literature on WCM (Baños-Caballero et al. 2012, 2014; Aktas et al. 2015). These are defined as firms with a Standard Industrial Classification (SIC) code between 6000 and 6900 (finance) and between 9000 and 9900 (administration). This leaves 58,588 firms. Next, we eliminate cases with missing value and errors. Due to the construction of one of our control variable (sales volatility), firm-year observations from the first two years are necessary to create the panel but not studied. The final sample includes 473,049 firm-year observations and 56,221 unique firms $^{6}$. Last, we should mention that we winsorize our data at the first and ninety-ninth percentiles to mitigate the impact of extreme values (Aktas et al. 2015).

\footnotetext{
${ }^{4}$ The calculation of one of our control variable, sales volatility motivates this choice. We acknowledge that this choice reduces the generalizability of our findings because many small firms, especially newly founded ones are excluded from the analysis.

${ }^{5}$ Germany is the country in Continental Europe with the shortest payment delays, while Italy is the one with the longest payment delays and France stands at the median (source: ECCBSO, Financial Statement Analysis Working Group).

${ }^{6}$ We provide a sample breakdown by country, years and industries as appendix A and B.
} 


\section{Measures}

Dependent variable. While other WCM studies use stock-price based measure to assess firm performance, we consider private companies and we cannot use the market value of equity or Tobin's Q as dependent variable (Baños-Caballero et al. 2014; Aktas et al. 2015). Therefore, following Deloof (2003) and Baños-Caballero et al. (2012), we use return on assets (ROA) as our main performance measure. We calculate ROA as operating income after financial expenses divided by total assets.

Independent variables. We consider WCM as our main variable of interest and we measure it through NOWC, which is equal to the sum of inventories and accounts receivables less accounts payable divided by total sales (Hill et al. 2010; Aktas et al. 2015). But a firm's level of NOWC largely depends on industry characteristics. Thus, we estimate the industry-adjusted NOWC as our independent variable (Aktas et al. 2015). To calculate it, we subtract from the NOWC of a given firm the annual median NOWC of the industry in which this firm operates and denote this variable IndAdjNowc. We use the 4-digit SIC codes to classify firms in their industries:

$$
\text { Industry }- \text { adjusted Nowc }=\text { NOWC }- \text { Annual industry median NOWC }
$$

When the industry-adjusted NOWC is positive, it means that the firm is adopting a conservative WCM and that it is overinvesting in NOWC. This suggests that a more efficient WCM, meaning a reduction of the NOWC, should result in higher performances. Of course, if the industryadjusted NOWC is negative, it means that the WCM is aggressive and that the risk of lost sales and opportunity costs is high (Aktas et al. 2015). This approach is intuitively based on the assumption that the optimal NOWC is the industry-median NOWC. 
Our primary goal is to identify if the sensitivity of firm performance to NOWC is moderated by firm size. Thus, we need to be able to distinguish between the sensitivity of a firm to a decrease in NOWC when the industry-adjusted NOWC is positive from its sensitivity to an increase in NOWC when industry-adjusted NOWC is negative. Both are expected to result in a higher level of performance. To capture these effects, we need to allow the slope in our models to be different for positive industry-adjusted NOWC and for negative industry-adjusted NOWC. Therefore, we create a dummy variable $\mathrm{D}$ which equals one if the industry-adjusted NOWC is positive and zero otherwise. Last, we calculate the interaction term between D and industry-adjusted NOWC, and the interaction term between one minus D and industry-adjusted NOWC.

In order to distinguish between different sizes, we create size categories. According to the criteria of the European Commission, we consider a firm as small if its number of employees is less than 50 and either its total assets or its sales revenue is less than $10 \mathrm{M} €$. We also define a medium firm as one with less than 250 employees and either less than $43 \mathrm{M} €$ of total assets or less than $50 \mathrm{M} €$ of sales. A firm that is neither small nor medium is thus large. This classification means that our sample includes approximately 34.96 percent of large firms, 44.47 percent of medium firms and 20.57 percent of small firms.

Control variables. Following Aktas et al. (2015), we use a large set of control variables known to affect firms' ROA. As we already discuss, the extent to which firms are financially constrained impacts the WCM-performance relationship (Kieschnick et al. 2013; Bañoscaballero et al. 2014). First, we control for the extent to which a firm is indebted and include Leverage, calculated as total financial debt divided by total assets, as a control variable. We also create a dummy Financial Distress which is equal to one if a firm meets two conditions and zero otherwise. First, it has to be overleveraged meaning that its leverage is in the top two deciles of its industry for a given year. Second, the cost of financial debt is high when compared 
to internally generated cash resources. Therefore, we calculate the interest coverage ratio as operating income plus depreciation and amortization divided by total interests paid. If the interest coverage ratio is lower than 0.8 during any given year or lower than 1 during two consecutive years, the second condition is met (Molina and Preve 2009; Hill et al. 2010; Aktas et al. 2015).

Cash ratio, calculated as cash and equivalents divided by total assets, is also included as a control variable because cash and NOWC are substitutes (Bates et al. 2009). As operating conditions impact WCM, we also control for Sales growth, which is the percentage change in sales between two consecutive years, and Sales volatility. Hill et al. (2010) indicate that it is difficult for firms to identify the appropriate level of inventory level to face an increase in sales volatility because it also depends on their trade credit policy and need for cash. Thus, Sales volatility which is the standard deviation of sales over a rolling five-year period scaled by total assets, is included as a control variable. Age is the natural logarithm of the number of years since firm's creation and is also a common control variable in the WCM literature as it indicates the bargaining power regarding payment delays (Baños-Caballero et al. 2010; Aktas et al. 2015). Size calculated as the natural logarithm of total assets is also included as an additional control variable (Baños-caballero et al. 2012).

Last, Fazzari and Petersen (1993) show that firms reduce investment in NOWC when internally generated cash decreases. This helps them to maintain constant the level of investment in fixed assets when availability of cash fluctuates. Therefore, we also introduce a control variable Fixed Assets which is the growth rate between two consecutive years in a firm's fixed assets.

\section{Results}


Table 1 presents the descriptive statistics and a correlation matrix. The average firm is 22.5 years old and holds $16.18 \mathrm{M} €$ of total assets and NOWC represents 18 percent of its total assets. This figure is in line with other WCM studies (Baños-Caballero et al. 2012; Aktas et al. 2015) As some correlations exist between our variables, we calculate the VIF to ensure that multicollinearity is not an issue with our data. The highest VIF is 1.20 which is well below the threshold of 10, so multicollinearity will not affect the results of our estimations.

\section{[Insert table 1 about here]}

We use a firm and year-fixed effects model to estimate the relationship between NOWC and firm performance measured as ROA. Table 2 shows the results for the regressions with robust standard errors clustered at the company level (Aktas et al. 2015). The first column shows the result for the entire sample. As expected, underinvestment in NOWC is positively related to ROA and overinvestment in NOWC is negatively related with ROA. This is consistent with the view that the relationship between NOWC and firm performance is concave. Our results corroborate those of Aktas et al. (2015) and Ben-Nasr (2016) who use the same methodology and they are also in line with those of Baños-Caballero et al. (2012, 2014).

\section{[Insert table 2 about here]}

The next three columns of table 2 present the results for large, medium and small firms subsamples. The sensitivity of performance to underinvestment is statistically significant for all the size buckets. We observe that the differences ${ }^{7}$ between the unstandardized coefficients are statistically significant at the 1 percent level when comparing small firms with medium and large firms. This means that small firms' performance is more sensitive to underinvestment in

\footnotetext{
${ }^{7}$ To estimate the existence of statistically significant differences between samples, we calculate the difference between the two samples coefficients divided by the square root of the sum of their squared errors. Then, we use a standard t-test to estimate whether or not the differences are statistically significant.
} 
NOWC than the one of medium or large firms. We do not observe that the performance of medium firms is more sensitive than the one of large firms to underinvestment in NOWC. The results support our $\mathrm{H} 1 \mathrm{a}$ and $\mathrm{H} 1 \mathrm{~b}$ hypotheses. However, while the sensitivity of performance to overinvestment is statistically significant for all the size buckets, there is no statistically significant difference between the unstandardized coefficients. Our results show therefore that the sensitivity of performance to NOWC is not different between large, medium and small firms when it comes to overinvestment. Thus, none of our $\mathrm{H} 2 \mathrm{a}, \mathrm{H} 2 \mathrm{~b}$ and $\mathrm{H} 2 \mathrm{c}$ hypotheses are validated. The economic significance of the results confirms this observation. Indeed, a one standard deviation decrease in overinvestment in NOWC is associated with a 0.29 percent increase in ROA for large firms, a 0.32 percent increase for medium firms and a 0.35 percent increase for small firms. However, the results are striking for small firms when it comes to underinvestment in NOWC. A one standard deviation increase in underinvestment in NOWC is associated with a 0.45 percent increase in ROA for large firms, a 0.52 percent increase for medium firms and a 0.93 percent increase for small firms.

\section{Robustness tests}

In this section, we perform several robustness tests to assess the validity of our results. First, as our sample includes firms from three different countries, institutional differences as well as economic conditions can have different impacts on our results. For example, there has been a banking crisis in Italy in recent years that likely affected Italian firms' access to banking debt and the subsequent cost of NOWC. We therefore estimate different regressions for the three countries and present the results in table 3 . In each country subsample, the industrymedian NOWC is calculated for firms operating in this very country as the optimal NOWC is likely different between the three countries ${ }^{8}$.

\footnotetext{
${ }^{8}$ We thank an anonymous referee for this remark.
} 


\section{[Insert table 3 about here]}

The French subsamples show similar results to those observed on the entire sample. The sensitivity of performance to underinvestment and overinvestment in NOWC is statistically significant and the difference between the coefficients for large and medium firms, medium and small, and large and small French firms is statistically significant. Hypothesis 1 is thus fully validated for the French subsample. The Italian subsamples only present statistically significant differences between large and small firms and large and medium firms for the sensitivity of performance to underinvestment in NOWC. Only the $\mathrm{H} 1 \mathrm{~b}$ and $\mathrm{H} 1 \mathrm{c}$ hypothesis are therefore confirmed for the Italian subsample. With respect to the German subsamples, we observe a statistically significant relationship between overinvestment in NOWC and performance for large and medium firms but not for small firms. We also observe no statistically significant relationship between underinvestment in NOWC and performance for small firms. Thus, we do not validate our hypothesesfor the German subsample.

The study of potential differences of size in the NOWC-performance relationship raises the question of potential omitted variables that could affect only firms of a particular size and not others. We identify affiliation to a business group (BG) as such a potential issue. Deloof and Jegers $(1996,1999)$ report trade credit, which is an important aspect of WCM, depends on a firm's affiliation to a BG. Indeed, firms affiliated to a BG can benefit from financial management at the group level that helps them improve WCM practices. Moreover, if one assumes a common financial management within a BG, it is likely that cash-rich affiliates extend more trade credit to cash-poor affiliates (Deloof and Jegers 1996). Thus, the optimal level of WCM for a single firm is not necessarily the same as for a firm that is affiliated to a BG. As BGs are a very common form of industrial organization in Western Europe, affiliation to a BG could obviously affect our results. Thus, we first create subsamples to distinguish 
between firms that are not affiliated to a BG (single firms), firms affiliated to a small BG (less than six subsidiaries), firms affiliated to a medium BG (more than six or less than twenty subsidiaries), and large BG (more than twenty subsidiaries). The thresholds we use to classify BG sizes are close to those set by Khanna and Palepu (2000). Then, we run our regressions on each of these subsamples. The results are provided in table 4 .

\section{[Insert table 4 about here]}

The relationship between the performance of single firms and overinvestment in NOWC is statistically significant for medium and small firms only. Regarding underinvestment in NOWC, there is a positive and significant relationship with the performance of single firms of all size. Moreover, there is a statistically significant difference between the sensitivity of small single firms and medium single firms, confirming our H1a hypothesis but not our H1b and $\mathrm{H} 1 \mathrm{c}$ hypotheses. We observe no statistically significant differences between firms affiliated to a small BG. However, we find support for our H1a hypotheses for both firms affiliated to medium and large BG. We also find support for our $\mathrm{H} 1 \mathrm{~b}$ in the case of large BG, indicating that the sensitivity of performance to underinvestment in NOWC is higher for small firms than for large firms. Overall, we find conclusive results except for the case of firms affiliated to small business groups.

We now turn the problem of potential endogeneity between performance and WCM. It is indeed possible that the observed level of NOWC which measures WCM is depends on firm performance. Thus, we use a two-stage regression approach to estimate the extent to which a firm overinvest or underinvest in NOWC as the residuals of a first-stage regression. This allows us to alleviate the concern that industry-median adjusted NOWC we use in the previous approach may not be a good estimation of the optimal NOWC. Building on the methodology suggested by Baños-Caballero et al. (2012) and Aktas et al. (2015), we estimate the excess 
investment in NOWC as the residuals of a first-stage regression. In this first-stage regression, we regress NOWC on Sales Growth, Sales Volatility, Age, Size, Financial Distress, Leverage, and country dummy variables for each industry/year. These variables are taken from Hill et al. (2010), Baños-Caballero et al. (2012) and Aktas et al. (2015). We exclude those industry/years for which we have less than 30 observations to ensure that we have enough observations to run the regressions so we end up with 3336 regressions. We do not report the results of these regressions for brevity but the average adjusted $\mathrm{R}^{2}$ is 31.27 percent, which is in the same range as Hill et al. (2010) and Aktas et al. (2015). Furthermore, the average F-statistics is 6.52 indicating that the regression model fits correctly the data. Next, we use the residuals of this first regression as the excess investment in NOWC and denote them ExcessNowc. This is our independent variable in our second-stage regression which is the same as in model 1 . Table 5 displays the results with ROA as dependent variable. The coefficients are statistically highly significant and the differences between them are also statistically significant in each case $(\mathrm{p}<.01$ between small firms and medium firms and between small firms and large firms and at $\mathrm{p}<.05$ between medium and large firms) regarding undervinvestment in NOWC. This brings additional credibility to our results ${ }^{9}$ as it provides support to all our hypotheses.

\section{[Insert table 5 about here]}

Last, Baños-Caballero et al. $(2012,2014)$ indicate that studies on the sensitivity of performance to NOWC should control for the influence of past values of performance on the current level of performance.. Thus, we re-estimate both our fixed-effects model and our twostage regression model with the generalized method of moments estimator developed by HoltzEakin et al. (1988) and Arellano and Bond (1991). This estimator uses lagged observations of the variables as instruments and is common in the WCM literature (Baños-Caballero et al. 2012,

\footnotetext{
${ }^{9} \mathrm{We}$ also re-estimate the regressions for the country-clusters and the business group affiliation clusters with this alternative approach and observe comparable results.
} 
2014). As our panel data includes a large number of individuals and a small number of time periods (large N, small T panels), this methodology is relevant in this study (Roodman, 2009).

We include all the right-hand-side variables of our model 1 lagged up to two times as instruments. To control for firm unobserved heterogeneity, we use the first difference in our observations and we include time-dummies to control for macroeconomic conditions that could affect firm performance. We use a Hansen test for over-identifying restriction to check that there is no correlation between our instruments and the error term, which is the case in all our specifications. We also report the Arellano-Bond $m_{2}$ statistic to test for the absence of second order serial correlation in the first difference residuals. Last, we indicate the results both for the one-step and two-step estimators with robust standard errors, the latter including Windmeijer's correction because the two-step estimator's standard errors are downward biased (Arellano and Bond 1991; Windmeijer 2005).

The results in table 6 show that the sensitivity of performance to NOWC is not significant for overinvestment in NOWC except for medium firms. This suggests that endogeneity indeed affects some our previous results and we find no support for our $\mathrm{H} 2$ hypothesis. However, the sensitivity of performance to NOWC for underinvestment remains statistically significant for the entire sample as well as for medium and small firms. While the coefficients indicate that the sensitivity of performance to NOWC is higher for small firms than for medium or large firms, the difference is not statistically significant at the conventional levels. However, the fact that there is no significant impact of underinvestment in NOWC on performance in the case of large firms but only for medium and small firms supports our H1b and H1c hypothesis.

In summary, we find support for our H1a and H1b hypotheses that the performance of small firms is more sensitive to underinvestment in NOWC than the one of medium and large 
firms. To a lesser extent, this is also true for medium firms when compared to large firms. However, we find no robust evidence that the performance of small firms is more sensitive to overinvestment in NOWC than the one of medium and large firms so we reject our $\mathrm{H} 2$ hypothesis.

\section{[Insert tables 6 and 7 about here]}

\section{Discussion}

In this paper, we study the impact of investment in NOWC on firm performance. While we observe that the performance of large, medium and small firm is influenced by underinvestment in NOWC, our results indicate no significant effect of overinvestment in NOWC after controlling for endogeneity. This contrasts with previous findings by BañosCaballero et al. (2012), Aktas et al. (2015) and Ben-Nasr (2016) who document that overinvestment in NOWC affects operating performances. As most of these studies consider observation periods that are prior to the Financial Crisis, it is possible that liquidity constraints after the crisis impacted WCM practices. More specifically, it is possible that most firms dramatically reduced investment in NOWC making the impact of overinvestment in NOWC on performance lower. Another possible argument to explain the differences between our results and those of previous studies is suggested by Aktas et al. (2015) who indicate a general decline in the levels of current assets over the last thirty years. The generalization of just-in-time inventory management is likely to explain these changes.

Our results do not demonstrate a difference in the sensitivity of performance to overinvestment in NOWC between small and large firms. This seems surprising as we expect small firms to have poorer WCM and less NOWC monitoring. Both should affect the sensitivity of performance both to underinvestment and to overinvestment. One possible explanation is that the monitoring argument is not valid when it comes to overinvestment in NOWC because 
smaller firms observe the costs of overinvestment in NOWC. But it is likely that they do not observe the opportunity costs of underinvestment in NOWC. This interpretation is consistent with Howorth and Westhead (2003) who indicate that small firms adjust their WCM only when cash availability is an issue. They find that small firms turn to WCM only when they need cash and that they cut investment in NOWC in this case. Moreover, Howorth and Westhead (2003) show that larger firms adjust WCM at the same speed than smaller firms when they need cash. This suggests that the sensitivity of performance to overinvestment in NOWC is close for small, medium and large privately held firms because they all rely heavily on internally generated cash.

We find that the sensitivity of performance to underinvestment in NOWC is higher for small firms than for large firms or medium firms. This means that small firms could improve their profitability by increasing investment in NOWC when they are currently underinvesting in NOWC because they would reduce opportunity costs of lost sales. This raises the question to know why they are currently underinvesting in NOWC. The first, and maybe the most obvious explanation, is that they don't have the skills or the time to do it (Peel and Wilson 1996; Peel et al. 2001). In other word, small firms managers don't realize the opportunity costs of underinvestment in NOWC precisely because they are not directly observable and they don't monitor NOWC often enough. However, it is also possible that managers decide to keep their investment in NOWC as low as possible because they believe this to be an efficient way of reducing the costs related to storage and to the financing of NOWC. In this case, our results clearly indicate the limitations of this reasoning. As small firms maintain low levels of inventory and accounts receivable, they increase the risk of stock-outs and potential customers choose other suppliers because they offer longer payment delays. This results in large opportunity costs for small firms. 
We believe that there is a third possible explanation. Consistent with the bootstrapping literature (Winborg and Landström 2001), small firms managers use customers-related techniques and late payment as financing sources when external financing is not available. It means that they keep a very low level of investment in NOWC, or even a negative NOWC, to finance investments in fixed assets or to face operating expenses. To put it short, WCM is driven by financial resources constraints for small firms. Our results show the limitations of such bootstrapping techniques because they result in lost sales which are more harmful for the performance of small firms than for the one of larger companies. This comes from the fact that small firms lack reputation more than large firms (Stinchcombe 1965; Aldrich and Auster 1986). Lost sales harm both small firms and large firms' profitability but they hinder small firms' growth more as it reduces potential reputation benefits of successful business transactions (Basdeo et al. 2006). Our results suggest that, despite the common wisdom on WCM that the lower the NOWC the better the performance, maintaining a low level of NOWC is not relevant for small firms. Moreover, we believe that small firms' managers should use only carefully bootstrapping techniques that constrain investment in NOWC and that external financing, while costly, offers a better cost-performance trade-off.

\section{Implications}

This paper has a number of implications for managers, policy makers and research.

For managers, our findings show that moving away from an optimal level of investment in NOWC reduces firm performance. In the case of small firms, underinvestment in NOWC is especially problematic. Contrary to the widespread view that investment in NOWC should be very low, we suggest that small firms invest more in NOWC to earn benefits related to increased sales and reputation. Additionally, a more frequent monitoring of WCM components is essential 
to regularly adjust investment in NOWC. From this perspective, relationships with the bank appear crucial. Jonsson and Lindbergh (2011) indicate that banks can bring financial management expertise to small firms' managers in addition to the financing of investments. Thus, small firms managers could benefit from bank's advices on WCM which would in turn help the bank to better assess the small firm's creditworthiness.

Our work has implications for policy makers as well. Hyttinen and Toivanen (2005) and Beck et al. (2008) show that the role of institutional environment is crucial for small firms to access external finance. More specifically, small, young and fast-growing firms benefit from governmental financial support and advice (Storey and Tether 1998; Fischer and Reuber 2003; Hyttinen and Toivanen 2005). However, Lee (2018) shows that there are limited benefits of government financial support to small firms on regional development. Thus, we suggest that policy makers consider more deeply the financing of NOWC of small and young firms when providing support to them. We interpret our results as indirect evidence that if small firms had have a better access to external finance but also a better guidance in financial management, they could have invested more in NOWC. This would have a direct effect on the performance of the firm that is government backed but also an indirect spillover effect on the firm's trade partners because of increased payment delays to customers.

Last, we contribute to the growing stream of research on working capital management as well as to the discussion on the liability of smallness. Our results corroborate previous findings by Baños-Caballero et al. (2012, 2014), Aktas et al. (2015) and others and extend them by considering mostly small and medium privately held firms. Furthermore, we show that size should be considered in future WCM research as it shapes the performance-WCM relationship. We also add to our understanding of factors that affect small firms' performances in general and not only high-tech or high-growth firms. Brush and Chaganti (1999) indicate that for these less "glamorous" firms, capabilities of the firm and resource-combination activities better 
explain small firms' performance than strategy. WCM is, we argue, closer to resourcemanagement activities than to strategy for small firms. Indeed, the greater sensitivity of performance to underinvestment in NOWC we observe is likely explained by the constraints faced by small firms in accessing external finance. Thus, their WCM is driven by the need for available money which means that as long as a firm cannot have access to external finance, it will maintain a low level of investment in NOWC. This affects the firm's performance. But it is also possible that small firms do not lack financial resources but only financial management and that their WCM is poor because it is only performed "whenever necessary" (Khoury et al. 1999). Both explanations are possible expressions of the liability of smallness.

\section{Limitations and future research}

This study has several limitations. The first, and maybe the most obvious one, is that we only observe the outcome of WCM through our NOWC measure and not WCM practices. Thus, we cannot distinguish between firms that have very different WCM practices resulting in the same level of NOWC. For example, we cannot distinguish between a financially constrained small firm that relies on bootstrapping finance and a less financially constrained firm that decides to maintain a very low level of investment in NOWC. Both of them would have the same sensitivity of performance to underinvestment in NOWC. We can only call for additional research on WCM that would be based on case-studies and surveys to understand how small firms manage WCM when they are financially constrained and the resulting impact on firm performance. While several papers explored WCM practices among small firms (Peel and Wilson 1996; Peel et al. 2001; Howorth and Westhead 2003), they focused on the US and the UK and they did not really consider WCM as a whole but rather its components. Moreover, they did not bridge WCM practices with the resulting performance. 
Another limitation comes from the fact that, while we study the role of size on the performance-NOWC relationships, our sample does not include a significant number of fastgrowing and high-tech firms. Therefore, our results cannot be fully generalized to this category of firms and future research could investigate the role and practices of WCM in start-ups and its relationship with bootstrapping techniques.

\section{Conclusion}

What explains firm performance? This question is at the core of research on management, strategy, finance and entrepreneurship. In this paper, we make a modest contribution to the literature as we provide empirical evidence on the role of size in the sensitivity of firm performance to investment in NOWC. Using a large sample of international firms, we show that small firms' performance is more sensitive to underinvestment in NOWC than the one of larger firms. Our goal was to demonstrate the role of WCM in our understanding of small firms' management and performance and to shed some light on this sometimes neglected aspect of financial management.

\section{References}

Aktas, N., E. Croci, and D. Petmezas (2015). "Is working capital management valueenhancing? Evidence from firm performance and investments," Journal of Corporate Finance 30(1), 98-113.

Aldrich, H.E., and E.R. Auster (1986). "Even dwarfs started small: Liabilities of age and size and their strategic implications," Research in organizational behavior, 8, 165-198. 
Arellano, M., and S. Bond (1991). "Some test specification for panel data: monte-carlo evidence and an application to employment equation," Review of Economic Studies, 58(2), 277-297.

Arend, R. L., and J. Wisner (2005). "Small business and supply chain management: is there a fit?,”. Journal of Business Venturing, 20(3), 403-436.

Audretsch, D.B., and J. Elston (1997). "Financing the German Mittelsand," Small Business Economics, 9(2), 97-110.

Baños-Caballero, S., P.J. Garcìa-Teruel, and P. Martìnez-Solano (2012). "How does working capital management affect the profitability of Spanish SMEs?," Small Business Economics, 39(2), 517-529.

Baños-Caballero, S., P.J. Garcìa-Teruel, and P. Martìnez-Solano (2014). "Working capital management, corporate performance, and financial constraints," Journal of Business Research, 67(3), 332-338.

Barney, J.B. (1991). "Firm resources and sustained competitive advantage," Journal of Management, 17(1), 99-120.

Basdeo, D.K., K.G. Smith, G.M. Grimm, V.P. Rindova, and P.J. Derfus (2006). "The impact of market actions on reputation,” Strategic Management Journal, 27(12), 1205-1219.

Bates, T., K. Kahle, and R. Stulz (2009). "Why do US firms hold so much more cash than they used to?," Journal of Finance, 64(5), 1985-2021.

Beck, T., A. Demirgüc-Kunt, and V. Maksimovic (2008). "Financing patterns around the world: are small firms different?," Journal of Financial Economics, 89(3), 467-487. 
Ben-Nasr, H. (2016). "State and foreign ownership and the value of working capital management," Journal of Corporate Finance, 41, 217-240.

Berger, A.N., and G.F. Udell (1998). "The economics of small business finance: the roles of private equity and debt markets in the financial growth cycle," Journal of Banking and Finance, 22(6), 613-673.

Berryman, J. (1983). "Small business failure and bankruptcy: A survey of the literature," European Small Business Journal, 1(4), 47-59.

Blinder, A.S., and L.J. Maccini (1991). "The resurgence of inventory research: What have we learned?," Journal of Economic Surveys, 5(4), 291-328.

Brinckmann, J., S. Salomo, and H.G. Gemuenden (2011). "Financial management competence of founding teams and growth of new technology-based firms," Entrepreneurship Theory and Practice, 35(2), 217-243.

Brush, C.G., and R. Chaganti (1999). "Business without glamour? An analysis of resources on performance by size and age in small service and retail firms," Journal of Business Venturing, 14(3), 233-257.

Cassar, G. (2004). “The financing of business start-ups,” Journal of Business Venturing, 19(2), 261-283.

Corsten, D., T. and Gruen (2004). “Stock-outs cause walkouts," Harvard Business Review, 82(5), 26-28.

Crook, T.R., and J.G. Combs (2007). "Sources and consequences of bargaining power in supply chains," Journal of Operations Management, 25, 546-555. 
Deloof, M., and M. Jegers (1996). “Trade credit, product quality, and intragroup trade: some European evidence," Financial Management, 25(3), 33-43.

Deloof, M., and M. Jegers (1999). "Trade credit, corporate groups, and the financing of Belgian firms," Journal of Business Finance and Accounting, 26(7), 945-966.

Deloof, M. (2003). "Does working capital management affect profitability of Belgian firms?," Journal of Business Accounting and Finance, 30(3), 573-587.

Dodge, H. R., S. Fullerton, and J.E. Robbins (1994). "Stage of the organizational life cycle and competition as mediators of problem perception for small businesses," Strategic Management Journal, 15(2), 121-134.

Ebben, J., and A. Johnson, (2006). "Bootstrapping in small firms: an empirical analysis of change over time," Journal of Business Venturing, 21(6), 851-865.

Ebben, J., and A. Johnson (2011). “Cash conversion cycle management in small firms: Relationships with liquidity, invested capital, and firm performance," Journal of Small Business and Entrepreneurship, 24(3), 381-396.

Fazzari, S.M., and Petersen B.C. (1993). "Working capital and fixed investment: new evidence on financing constraints," RAND Journal of Economics, 24(3), 328-342.

Fischer, E., and A.R. Reuber (2003). "Support for rapid-growth firms: a comparison of the views of founders, government policymakers, and private sector resource providers," Journal of Small Business Management, 41(4), 346-365.

Graham, J.R., and C.R. Harvey (2001). “The theory and practice of corporate finance: evidence from the field," Journal of Financial Economics, 60(2), 187-243.

Hill, M.D., G.W. Kelly, and M.J. Highfield (2010). "Net operating working capital behaviour: A first look," Financial Management, 39(2), 783-805. 
Holtz-Eakin, D., W. Newey, and H.S. Rosen (1988). "Estimating vector autoregressions with panel data," Econometrica, 56(6), 1371-1395.

Howorth, C. (2001). "Small firms' demand for finance: a research note," International Small Business Journal, 19(4), 78-86.

Howorth, C., and P. Westhead (2003). "The focus on working capital management in UK small firms," Management Accounting Research, 14(2), 94-111.

Hyttinen, A., and O. Toivanen (2005). "Do financial constraints hold back innovation and growth?: Evidence on the role of public policy," Research Policy, 34(9), 1385-1403.

Jonsson S., and J. Lindbergh (2011). "The development of social capital and financing of entrepreneurial firms: from financial bootstrapping to bank lending," Entrepreneurship Theory and Practice, 37(4), 661-686.

Khanna, T., and K. Palepu (2000). "Is group affiliation profitable in emerging markets? An analysis of diversified Indian business groups,” Journal of Finance, 54(2), 867-891.

Khoury, N.T., K.V. Smith and P. McKay (1999). “Comparing working capital practices in Canada, the United States, and Australia: a note," Revue Canadienne des Sciences de l'Administration, 16(1), 53-57.

Kieschnick, R., M. Laplante, and R. Moussawi (2013). "Working capital management and shareholder's wealth," Review of Finance, 17(5), 1827-1852.

Kim, Y. H., and K.H. Chung (1990). “An integrated evaluation of investment in inventory and credit: A cash flow approach,” Journal of Business Finance and Accounting, 17(3), 381-390.

Lee, Y.W., and J.D. Stowe (1993). "Product risk, asymmetric information, and trade credit," Journal of Financial and Quantitative Analysis, 28(2), 285-300. 
Lee, Y.S., (2018). “Government guaranteed small business loans and regional growth,” Journal of Business Venturing, 33(1), 70-83.

Long, M. S., I.B. Malitz, and S.A. Ravid, (1993). “Trade credit, quality guarantees, and product marketability," Financial Management, 22(4), 117-127.

Molina, C.A., and L.A. Preve (2009). "Trade receivable policy of distressed firms and its effects on the costs of financial distress," Financial Management, 38(3), 663-686.

Ng, C.K., J.K. Smith, and R.L. Smith, (1999). "Evidence on the determinants of trade credit terms used in interfirm trade," Journal of Finance, 54(3), 1109-1129.

Peel, M.J., and N. Wilson (1996). "Working capital and financial management practices in small firms," International Journal of Small Business, 14(2), 52-68.

Peel, M.J., N. Wilson, and C. Howorth (2001). "Late payment and trade credit management in small firm sector: Some empirical evidence," International Journal of Small Business, 18(2), 17-37.

Penrose, E. (1959). The theory of the growth of the firm. New-York: Oxford University Press. Roodman, D. (2009). "How to do xtabond2: an introduction to difference and system GMM in Stata," Stata Journal, 9(1), 86-136.

Shipley, D., and L. Davis, (1991). "The role and burden-allocation of credit in distribution channels," Journal of Marketing Channels, 1, 3-22.

Stiglitz, J., and A. Weiss (1983). "Incentive effects of terminations: applications to the credit and labor markets," American Economic Review, 73(5), 912-927.

Stinchcombe, A.L. (1965). Social structures and organizations. In March J.P. (Ed), Handbook of organizations (pp.142-193), Rand McNally, Chicago. 
Storey, D.J., and B.S. Tether (1998). "Public policy measures to support new technologybased firms in the European Union," Research Policy, 26(9), 1037-1057.

Wernerfelt, B. (1984). “A resource-based view of the firm," Strategic Management Journal, 5(2), 171-180.

Wilson, N., and B. Summers (2002). "Trade credit terms offered by small firms: Survey evidence and empirical analysis," Journal of Business Finance and Accounting, 29(3), 317351.

Winborg, J., and Landström, H. (2001). "Financial bootstrapping in small businesses:

Examining small business managers' resource acquisition behaviors," Journal of Business Venturing, 16(3), 235-254.

Windmeijer, F. (2005). "A finite sample correction for the variance of linear efficient twostep GMM estimators," Journal of Econometrics, 126(1), 25-51. 
Table 1

Descriptive statistics and correlation table

\begin{tabular}{|c|c|c|c|c|c|c|c|c|c|c|c|c|c|c|}
\hline & & Mean & Median & SD & 1 & 2 & 3 & 4 & 5 & 6 & 7 & 8 & 9 & 10 \\
\hline 1 & Nowc & 0.18 & 0.13 & 0.24 & & & & & & & & & & \\
\hline 2 & Ind Adj Nowc & 0.04 & 0.00 & 0.22 & 0.93 & & & & & & & & & \\
\hline 3 & ROA & 0.05 & 0.04 & 0.10 & -0.06 & -0.07 & & & & & & & & \\
\hline 4 & Sales Growth & 0.08 & 0.03 & 0.32 & $-\mathbf{0 . 0 3}$ & -0.03 & 0.09 & & & & & & & \\
\hline 5 & Leverage & 0.15 & 0.08 & 0.18 & 0.14 & 0.15 & -0.23 & -0.01 & & & & & & \\
\hline 6 & Size & 9.69 & 9.43 & 1.26 & 0.16 & 0.12 & -0.09 & -0.04 & 0.06 & & & & & \\
\hline 7 & Fixed Assets & 0.14 & 0.00 & 0.69 & -0.01 & -0.01 & 0.03 & 0.17 & 0.00 & -0.03 & & & & \\
\hline 8 & Age & 3.12 & 3.14 & 0.69 & 0.09 & 0.05 & 0.00 & -0.14 & 0.00 & 0.20 & -0.09 & & & \\
\hline 9 & Sales Volatility & 0.16 & 0.12 & 0.16 & 0.17 & 0.15 & -0.13 & 0.10 & 0.01 & -0.01 & 0.07 & -0.16 & & \\
\hline 10 & Cash Ratio & 0.10 & 0.05 & 0.13 & -0.16 & -0.14 & 0.25 & 0.02 & -0.26 & -0.17 & 0.01 & -0.02 & 0.00 & \\
\hline 11 & Financial Distress & 0.03 & 0.00 & 0.16 & 0.05 & 0.05 & -0.25 & -0.03 & $\mathbf{0 . 3 0}$ & 0.04 & 0.00 & -0.01 & 0.08 & -0.07 \\
\hline
\end{tabular}

$\mathrm{N}=473,049$. Correlation coefficient significant at $\mathrm{p}<0.05$ are shown in bold.

$\mathrm{SD}$, standard deviation. 


\section{Table 2}

Fixed effects regressions of the impact of net operating working capital on firm operating performance by firm size

\begin{tabular}{|c|c|c|c|c|}
\hline $\begin{array}{l}\text { ROA is the dependent } \\
\text { variable }\end{array}$ & All firms & Large firms & Medium firms & Small firms \\
\hline \multirow[t]{2}{*}{ Ind Adj Nowc * D } & $-0.017 * * *$ & $-0.016 * * *$ & $-0.016 * * *$ & $-0.020 * * *$ \\
\hline & 0.002 & 0.003 & 0.002 & 0.004 \\
\hline \multirow[t]{2}{*}{ Ind Adj Nowc * (1-D) } & $0.080 * * *$ & $0.058 * * *$ & $0.071 * * *$ & $0.118 * * *$ \\
\hline & 0.004 & 0.007 & 0.006 & 0.008 \\
\hline \multirow[t]{2}{*}{ Sales growth } & $0.022 * * *$ & $0.020 * * *$ & $0.025 * * *$ & $0.023 * * *$ \\
\hline & 0.001 & 0.001 & 0.001 & 0.001 \\
\hline \multirow[t]{2}{*}{ Leverage } & $-0.082 * * *$ & $-0.067 * * *$ & $-0.092 * * *$ & $-0.093 * * *$ \\
\hline & 0.002 & 0.003 & 0.003 & 0.004 \\
\hline \multirow[t]{2}{*}{ Size } & $0.008 * * *$ & $0.005 * * *$ & $0.011 * * *$ & $0.014 * * *$ \\
\hline & 0.001 & 0.001 & 0.001 & 0.002 \\
\hline \multirow[t]{2}{*}{ Fixed assets } & $0.001 * * *$ & 0.000 & $0.001 * * *$ & $0.001 * *$ \\
\hline & 0.000 & 0.000 & 0.000 & 0.000 \\
\hline \multirow[t]{2}{*}{ Age } & $0.010 * * *$ & $0.010 * * *$ & $0.011 * * *$ & 0.001 \\
\hline & 0.002 & 0.003 & 0.002 & 0.003 \\
\hline \multirow[t]{2}{*}{ Sales volatility } & $-0.050 * * *$ & $-0.055 * * *$ & $-0.055 * * *$ & $-0.046 * * *$ \\
\hline & 0.002 & 0.003 & 0.002 & 0.004 \\
\hline \multirow[t]{2}{*}{ Cash ratio } & $0.124 * * *$ & $0.106 * * *$ & $0.118 * * *$ & $0.128 * * *$ \\
\hline & 0.003 & 0.005 & 0.004 & 0.005 \\
\hline \multirow[t]{2}{*}{ Financial distress } & $-0.076 * * *$ & $-0.076 * * *$ & $-0.073 * * *$ & $-0.071 * * *$ \\
\hline & 0.001 & 0.002 & 0.002 & 0.003 \\
\hline Firm fixed effects & YES & YES & YES & YES \\
\hline Year fixed effects & YES & YES & YES & YES \\
\hline $\begin{array}{l}\text { Number of } \\
\text { observations }\end{array}$ & 473,049 & 165,396 & 210,365 & 97,288 \\
\hline F-statistics & $736.59 * * *$ & $206.09 * * *$ & $349.02 * * *$ & $171.31 * * *$ \\
\hline Adjusted $\mathrm{R}^{2}$ & 0.688 & 0.740 & 0.732 & 0.738 \\
\hline
\end{tabular}

$* \mathrm{p}<0.1, * * \mathrm{p}<0.05, * * * \mathrm{p}<0.01$.

Errors are robust and clustered at the firm level. We report them under the coefficients. 
Table 3

Fixed effects regressions of the impact of net operating working capital on firm operating performance by firm size and country clusters

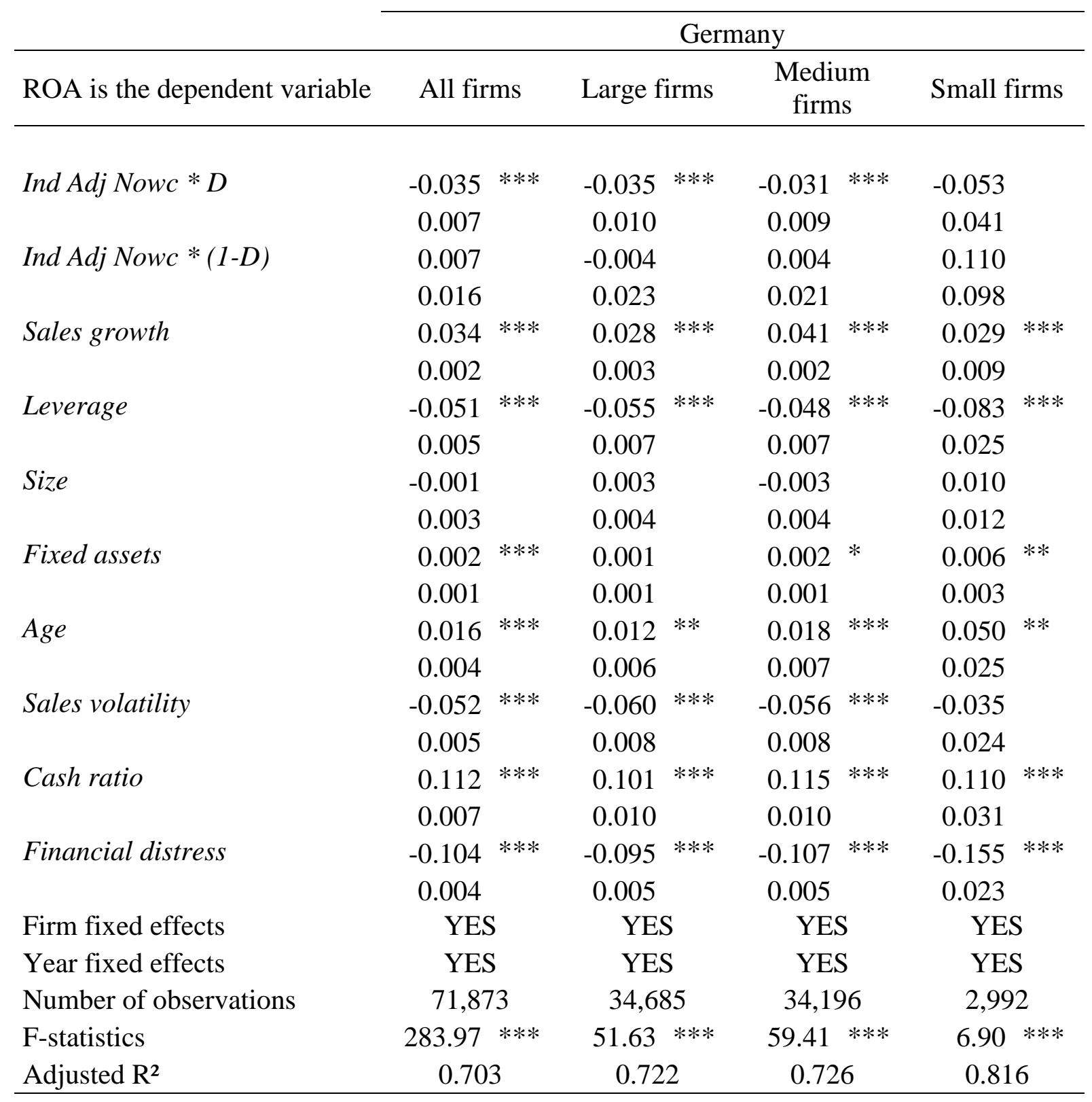

$* \mathrm{p}<0.1, * * \mathrm{p}<0.05, * * * \mathrm{p}<0.01$.

Errors are robust and clustered at the firm level. We report them under the coefficients. 


\section{France}

ROA is the dependent variable

\begin{tabular}{|c|c|c|c|c|c|c|c|c|}
\hline \multirow[t]{2}{*}{ Ind Adj Nowc * D } & -0.020 & $* * *$ & -0.017 & $* * *$ & -0.023 & $* * *$ & -0.026 & $* * *$ \\
\hline & 0.003 & & 0.004 & & 0.005 & & 0.008 & \\
\hline \multirow[t]{2}{*}{ Ind Adj Nowc * $(1-D)$} & 0.124 & $* * *$ & 0.091 & $* * *$ & 0.114 & $* * *$ & 0.213 & $* * *$ \\
\hline & 0.007 & & 0.009 & & 0.012 & & 0.020 & \\
\hline \multirow[t]{2}{*}{ Sales growth } & 0.024 & $* * *$ & 0.021 & $* * *$ & 0.024 & $* * *$ & 0.031 & $* * *$ \\
\hline & 0.001 & & 0.001 & & 0.001 & & 0.002 & \\
\hline \multirow[t]{2}{*}{ Leverage } & -0.081 & $* * *$ & -0.072 & $* * *$ & -0.081 & $* * *$ & -0.116 & $* * *$ \\
\hline & 0.003 & & 0.004 & & 0.005 & & 0.007 & \\
\hline \multirow[t]{2}{*}{ Size } & 0.009 & $* * *$ & 0.009 & $* * *$ & 0.019 & $* * *$ & 0.011 & $* * *$ \\
\hline & 0.001 & & 0.002 & & 0.002 & & 0.003 & \\
\hline \multirow[t]{2}{*}{ Fixed assets } & 0.000 & & 0.000 & & 0.000 & & -0.001 & \\
\hline & 0.000 & & 0.000 & & 0.001 & & 0.001 & \\
\hline \multirow[t]{2}{*}{ Age } & 0.007 & $* * *$ & 0.006 & & 0.016 & $* * *$ & 0.001 & \\
\hline & 0.003 & & 0.004 & & 0.005 & & 0.006 & \\
\hline \multirow[t]{2}{*}{ Sales volatility } & -0.061 & $* * *$ & -0.060 & $* * *$ & -0.070 & $* * *$ & -0.059 & $* * *$ \\
\hline & 0.003 & & 0.004 & & 0.004 & & 0.007 & \\
\hline \multirow[t]{2}{*}{ Cash ratio } & 0.130 & $* * *$ & 0.116 & $* * *$ & 0.128 & $* * *$ & 0.142 & $* * *$ \\
\hline & 0.004 & & 0.006 & & 0.006 & & 0.008 & \\
\hline \multirow[t]{2}{*}{ Financial distress } & -0.076 & $* * *$ & -0.074 & $* * *$ & -0.070 & $* * *$ & -0.079 & $* * *$ \\
\hline & 0.002 & & 0.003 & & 0.003 & & 0.005 & \\
\hline Firm fixed effects & YES & & YES & & YES & & YES & \\
\hline Year fixed effects & YES & & YES & & YES & & YES & \\
\hline Number of observations & 203,49 & & 94,398 & & 70,056 & & 39,036 & \\
\hline F-statistics & 291.59 & $* * *$ & 123.17 & $* * *$ & 102.58 & $* * *$ & 69.28 & $* * *$ \\
\hline Adjusted $\mathrm{R}^{2}$ & 0.694 & & 0.750 & & 0.742 & & 0.751 & \\
\hline
\end{tabular}


Italy

ROA is the dependent variable

All firms Large firms Medium firms Small firms

\begin{tabular}{|c|c|c|c|c|c|c|c|c|}
\hline \multirow[t]{2}{*}{ Ind Adj Nowc $* D$} & -0.013 & $* * *$ & -0.012 & $* * *$ & -0.012 & $* * *$ & -0.017 & $* * *$ \\
\hline & 0.002 & & 0.004 & & 0.003 & & 0.005 & \\
\hline \multirow[t]{2}{*}{ Ind Adj Nowc * (1-D) } & 0.049 & $* * *$ & 0.025 & $* * *$ & 0.049 & $* * *$ & 0.062 & $* * *$ \\
\hline & 0.004 & & 0.009 & & 0.005 & & 0.007 & \\
\hline \multirow[t]{2}{*}{ Sales growth } & 0.018 & $* * *$ & 0.014 & $* * *$ & 0.021 & $* * *$ & 0.019 & $* * *$ \\
\hline & 0.001 & & 0.001 & & 0.001 & & 0.001 & \\
\hline \multirow[t]{2}{*}{ Leverage } & -0.094 & $* * *$ & -0.059 & $* * *$ & -0.120 & $* * *$ & -0.082 & $* * *$ \\
\hline & 0.003 & & 0.007 & & 0.004 & & 0.004 & \\
\hline \multirow[t]{2}{*}{ Size } & 0.010 & $* * *$ & -0.003 & & 0.011 & $* * *$ & 0.016 & $* * *$ \\
\hline & 0.001 & & 0.003 & & 0.002 & & 0.002 & \\
\hline \multirow[t]{2}{*}{ Fixed assets } & 0.001 & $* * *$ & 0.001 & & 0.001 & $* * *$ & 0.001 & $* * *$ \\
\hline & 0.000 & & 0.001 & & 0.000 & & 0.000 & \\
\hline \multirow[t]{2}{*}{ Age } & 0.006 & $* * *$ & 0.012 & $* *$ & 0.002 & & -0.003 & \\
\hline & 0.002 & & 0.005 & & 0.003 & & 0.004 & \\
\hline \multirow[t]{2}{*}{ Sales volatility } & -0.041 & $* * *$ & -0.040 & $* * *$ & -0.046 & $* * *$ & -0.039 & $* * *$ \\
\hline & 0.002 & & 0.005 & & 0.003 & & 0.004 & \\
\hline \multirow[t]{2}{*}{ Cash ratio } & 0.113 & $* * *$ & 0.071 & $* * *$ & 0.103 & $* * *$ & 0.112 & $* * *$ \\
\hline & 0.004 & & 0.011 & & 0.005 & & 0.007 & \\
\hline \multirow[t]{2}{*}{ Financial distress } & -0.068 & $* * *$ & -0.067 & $* * *$ & -0.066 & $* * *$ & -0.063 & $* * *$ \\
\hline & 0.001 & & 0.003 & & 0.002 & & 0.003 & \\
\hline Firm fixed effects & YES & & YES & & YES & & YES & \\
\hline Year fixed effects & YES & & YES & & YES & & YES & \\
\hline Number of observations & 197,686 & & 36,313 & & 106,11 & & 55,260 & \\
\hline F-statistics & 1225.71 & $* * *$ & 121.07 & $* * *$ & 228.90 & $* * *$ & 114.16 & $* * *$ \\
\hline Adjusted $\mathrm{R}^{2}$ & 0.668 & & 0.728 & & 0.726 & & 0.715 & \\
\hline
\end{tabular}




\section{Table 4}

Fixed effects regressions of the impact of net operating working capital on firm operating performance by business group affiliation and firm size

\section{Large firms}

\begin{tabular}{|c|c|c|c|c|c|c|c|c|}
\hline \multirow{2}{*}{$\begin{array}{l}\text { ROA is the dependent } \\
\text { variable } \\
\text { Ind Adj Nowc *D }\end{array}$} & \multicolumn{2}{|c|}{ Large BG } & \multicolumn{2}{|c|}{ Medium BG } & \multicolumn{2}{|c|}{ Small BG } & \multicolumn{2}{|c|}{$\begin{array}{c}\text { Not affiliated } \\
\text { to a } B G\end{array}$} \\
\hline & -0.024 & $* * *$ & -0.008 & & -0.008 & & 0.000 & \\
\hline & 0.004 & & 0.008 & & 0.006 & & 0.006 & \\
\hline \multirow[t]{2}{*}{ Ind Adj Nowc * $(1-D)$} & 0.035 & $* * *$ & 0.083 & $* * *$ & 0.088 & $* * *$ & 0.102 & $* * *$ \\
\hline & 0.009 & & 0.019 & & 0.014 & & 0.017 & \\
\hline \multirow[t]{2}{*}{ Sales growth } & 0.019 & $* * *$ & 0.023 & $* * *$ & 0.021 & $* * *$ & 0.020 & $* * *$ \\
\hline & 0.001 & & 0.002 & & 0.002 & & 0.002 & \\
\hline \multirow[t]{2}{*}{ Leverage } & -0.055 & $* * *$ & -0.070 & $* * *$ & -0.096 & $* * *$ & -0.063 & $* * *$ \\
\hline & 0.004 & & 0.008 & & 0.007 & & 0.009 & \\
\hline \multirow[t]{2}{*}{ Size } & 0.006 & $* * *$ & 0.002 & & 0.006 & $* *$ & 0.002 & \\
\hline & 0.002 & & 0.004 & & 0.003 & & 0.003 & \\
\hline \multirow[t]{2}{*}{ Fixed assets } & 0.000 & & 0.001 & & 0.000 & & 0.000 & \\
\hline & 0.001 & & 0.001 & & 0.001 & & 0.001 & \\
\hline \multirow[t]{2}{*}{ Age } & 0.017 & $* * *$ & 0.014 & $* *$ & 0.000 & & -0.007 & \\
\hline & 0.004 & & 0.006 & & 0.005 & & 0.007 & \\
\hline \multirow[t]{2}{*}{ Sales volatility } & -0.056 & $* * *$ & -0.062 & $* * *$ & -0.055 & $* * *$ & -0.030 & $* * *$ \\
\hline & 0.004 & & 0.008 & & 0.006 & & 0.008 & \\
\hline \multirow[t]{2}{*}{ Cash ratio } & 0.073 & $* * *$ & 0.117 & $* * *$ & 0.141 & $* * *$ & 0.134 & $* * *$ \\
\hline & 0.008 & & 0.011 & & 0.008 & & 0.011 & \\
\hline \multirow[t]{2}{*}{ Financial distress } & -0.074 & $* * *$ & -0.084 & $* * *$ & -0.084 & $* * *$ & -0.067 & $* * *$ \\
\hline & 0.003 & & 0.005 & & 0.004 & & 0.006 & \\
\hline Firm fixed effects & YES & & YES & & YES & & YES & \\
\hline Year fixed effects & YES & & YES & & YES & & YES & \\
\hline Number of observations & 76,48 & & 29,11 & & 40,98 & & 18,81 & \\
\hline F-statistics & 226.23 & $* * *$ & 45.77 & $* * *$ & 76.40 & $* * *$ & 25.24 & $* * *$ \\
\hline Adjusted R² & 0.72 & & 0.74 & & 0.75 & & 0.76 & \\
\hline
\end{tabular}

$* \mathrm{p}<0.1, * * \mathrm{p}<0.05, * * * \mathrm{p}<0.01$.

Errors are robust and clustered at the firm level. We report them under the coefficients. 
Table 4 (continued)

Medium firms

ROA is the dependent variable

Large BG Medium BG Small BG Not affiliated to a BG

\begin{tabular}{|c|c|c|c|c|c|c|c|c|}
\hline \multirow[t]{2}{*}{ Ind Adj Nowc * D } & -0.018 & $* * *$ & -0.016 & $* * *$ & -0.013 & $* * *$ & -0.013 & $* * *$ \\
\hline & 0.005 & & 0.005 & & 0.003 & & 0.004 & \\
\hline \multirow[t]{2}{*}{ Ind Adj Nowc * $(1-D)$} & 0.066 & $* * *$ & 0.076 & $* * *$ & 0.082 & $* * *$ & 0.069 & $* * *$ \\
\hline & 0.011 & & 0.014 & & 0.009 & & 0.011 & \\
\hline \multirow[t]{2}{*}{ Sales growth } & 0.027 & $* * *$ & 0.026 & $* * *$ & 0.024 & $* * *$ & 0.022 & $* * *$ \\
\hline & 0.001 & & 0.002 & & 0.001 & & 0.002 & \\
\hline \multirow[t]{2}{*}{ Leverage } & -0.060 & $* * *$ & -0.089 & $* * *$ & -0.123 & $* * *$ & -0.108 & $* * *$ \\
\hline & 0.005 & & 0.007 & & 0.005 & & 0.006 & \\
\hline \multirow[t]{2}{*}{ Size } & 0.008 & $* * *$ & 0.011 & $* * *$ & 0.014 & $* * *$ & 0.014 & $* * *$ \\
\hline & 0.002 & & 0.003 & & 0.002 & & 0.003 & \\
\hline \multirow[t]{2}{*}{ Fixed assets } & 0.000 & & 0.002 & $* * *$ & 0.001 & $* * *$ & 0.001 & $* *$ \\
\hline & 0.001 & & 0.001 & & 0.000 & & 0.001 & \\
\hline \multirow[t]{2}{*}{ Age } & 0.022 & $* * *$ & 0.013 & $* *$ & 0.001 & & 0.001 & \\
\hline & 0.005 & & 0.006 & & 0.004 & & 0.005 & \\
\hline \multirow[t]{2}{*}{ Sales volatility } & -0.067 & $* * *$ & -0.053 & $* * *$ & -0.046 & $* * *$ & -0.038 & $* * *$ \\
\hline & 0.004 & & 0.006 & & 0.004 & & 0.005 & \\
\hline \multirow[t]{2}{*}{ Cash ratio } & 0.088 & $* * *$ & 0.140 & $* * *$ & 0.135 & $* * *$ & 0.121 & $* * *$ \\
\hline & 0.007 & & 0.010 & & 0.006 & & 0.009 & \\
\hline \multirow[t]{2}{*}{ Financial distress } & -0.084 & $* * *$ & -0.075 & $* * *$ & -0.070 & $* * *$ & -0.061 & $* * *$ \\
\hline & 0.003 & & 0.004 & & 0.003 & & 0.004 & \\
\hline Firm fixed effects & \multicolumn{2}{|c|}{ YES } & \multicolumn{2}{|c|}{ YES } & \multicolumn{2}{|c|}{ YES } & \multicolumn{2}{|c|}{ YES } \\
\hline Year fixed effects & \multicolumn{2}{|c|}{ YES } & \multicolumn{2}{|c|}{ YES } & \multicolumn{2}{|c|}{ YES } & \multicolumn{2}{|c|}{ YES } \\
\hline Number of observations & \multicolumn{2}{|c|}{63,460} & \multicolumn{2}{|c|}{38,703} & \multicolumn{2}{|c|}{73,346} & \multicolumn{2}{|c|}{34,856} \\
\hline F-statistics & \multicolumn{2}{|c|}{$97.98 * * *$} & \multicolumn{2}{|c|}{$67.05 * * *$} & \multicolumn{2}{|c|}{$163.38 * * *$} & \multicolumn{2}{|c|}{$213.54 * * *$} \\
\hline Adjusted $\mathrm{R}^{2}$ & \multicolumn{2}{|c|}{0.729} & \multicolumn{2}{|c|}{0.711} & \multicolumn{2}{|c|}{0.743} & \multicolumn{2}{|c|}{0.770} \\
\hline
\end{tabular}


Table 4 (continued)

Small firms

ROA is the dependent variable
Large BG Medium BG
Not affiliated to a BG

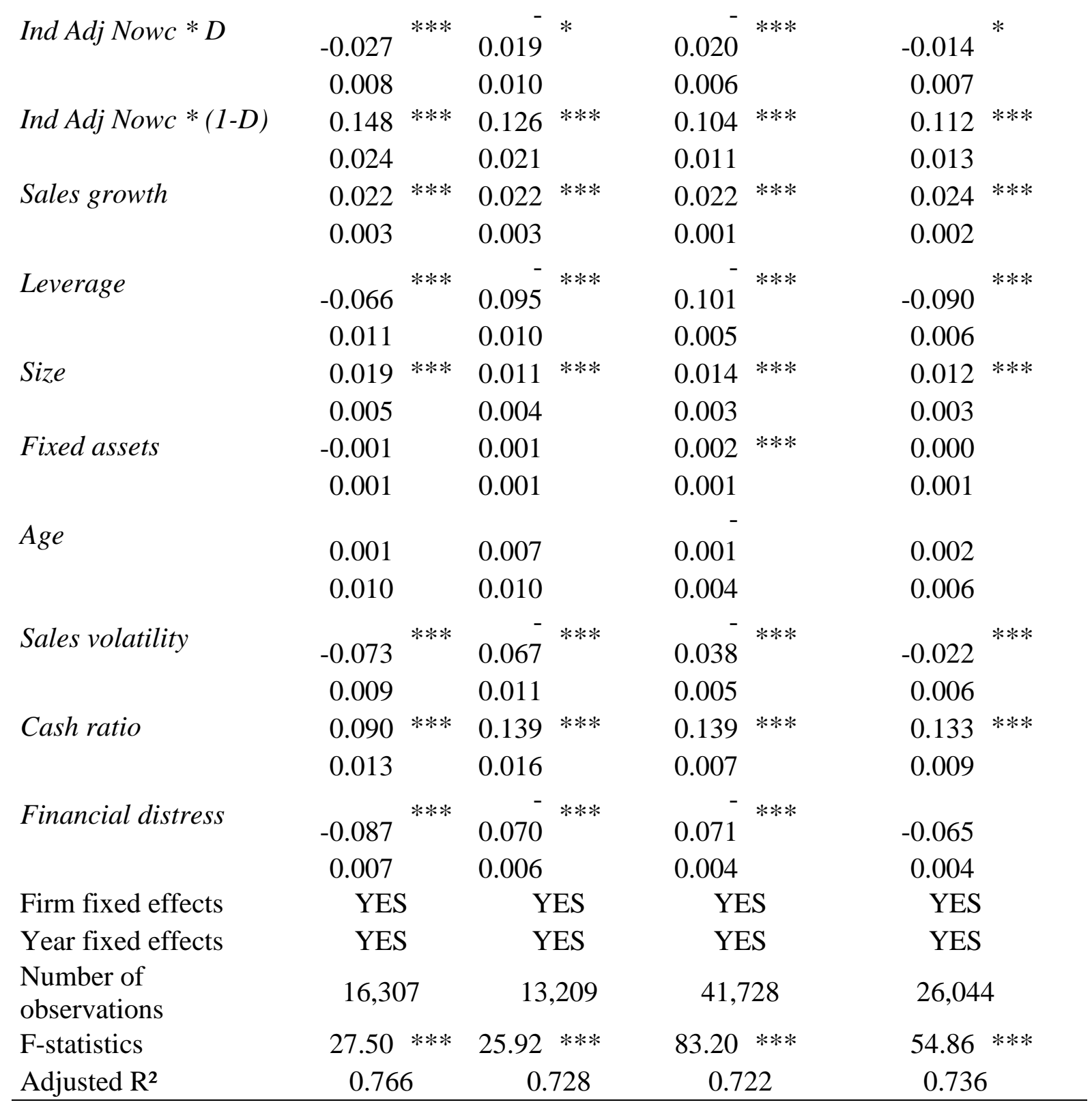




\section{Table 5}

Fixed effects regressions of the impact of regression based net operating working capital on firm operating performance by firm size

ROA is the dependent variable

\section{All firms Large firms Medium firms Small firms}

\begin{tabular}{|c|c|c|c|c|c|c|c|c|}
\hline \multirow[t]{2}{*}{$\operatorname{ExcessNwc} * D$} & -0.026 & $* * *$ & -0.025 & $* * *$ & -0.027 & $* * *$ & -0.030 & $* * *$ \\
\hline & 0.002 & & 0.004 & & 0.002 & & 0.004 & \\
\hline \multirow[t]{2}{*}{ ExcessNwc * $(1-D)$} & 0.071 & $* * *$ & 0.052 & $* * *$ & 0.068 & $* * *$ & 0.102 & $* * *$ \\
\hline & 0.003 & & 0.005 & & 0.005 & & 0.007 & \\
\hline \multirow[t]{2}{*}{ Sales growth } & 0.021 & $* * *$ & 0.019 & $* * *$ & 0.024 & $* * *$ & 0.021 & $* * *$ \\
\hline & 0.001 & & 0.001 & & 0.001 & & 0.001 & \\
\hline \multirow[t]{2}{*}{ Leverage } & -0.077 & $* * *$ & -0.063 & $* * *$ & -0.089 & $* * *$ & -0.086 & $* * *$ \\
\hline & 0.002 & & 0.004 & & 0.003 & & 0.004 & \\
\hline \multirow[t]{2}{*}{ Size } & 0.010 & $* * *$ & 0.006 & $* * *$ & 0.012 & $* * *$ & 0.017 & $* * *$ \\
\hline & 0.001 & & 0.002 & & 0.001 & & 0.002 & \\
\hline \multirow[t]{2}{*}{ Fixed assets } & 0.001 & $* * *$ & 0.000 & & 0.001 & $* * *$ & 0.001 & $* *$ \\
\hline & 0.000 & & 0.000 & & 0.000 & & 0.000 & \\
\hline \multirow[t]{2}{*}{ Age } & 0.010 & $* * *$ & 0.011 & $* * *$ & 0.009 & $* * *$ & 0.003 & \\
\hline & 0.002 & & 0.003 & & 0.002 & & 0.004 & \\
\hline \multirow[t]{2}{*}{ Sales volatility } & -0.042 & $* * *$ & -0.048 & $* * *$ & -0.047 & $* * *$ & -0.033 & $* * *$ \\
\hline & 0.002 & & 0.003 & & 0.002 & & 0.003 & \\
\hline \multirow[t]{2}{*}{ Cash ratio } & 0.123 & $* * *$ & 0.105 & $* * *$ & 0.117 & $* * *$ & 0.125 & $* * *$ \\
\hline & 0.003 & & 0.004 & & 0.004 & & 0.005 & \\
\hline \multirow[t]{2}{*}{ Financial distress } & -0.077 & $* * *$ & -0.077 & $* * *$ & -0.074 & $* * *$ & -0.073 & $* * *$ \\
\hline & 0.001 & & 0.002 & & 0.002 & & 0.003 & \\
\hline Firm fixed effects & YES & & YES & & YES & & YES & \\
\hline Year fixed effects & YES & & YES & & YES & & YES & \\
\hline Number of observations & 450,69 & & 157,28 & & 199,296 & & 94,110 & 0 \\
\hline F-statistics & 23012.68 & $* * *$ & 6545.03 & $* * *$ & 22756.80 & $* * *$ & 6304.72 & $* * *$ \\
\hline Adjusted R² & 0.688 & & 0.741 & & 0.733 & & 0.738 & \\
\hline
\end{tabular}

$* \mathrm{p}<0.1, * * \mathrm{p}<0.05, * * * \mathrm{p}<0.01$.

Errors are bootstrapped because Excess $N w c$ is estimated in a first-stage regression. We report them under the coefficients. 
Table 6

Dynamic panel data estimations of the impact of net operating working capital on firm operating performance

\begin{tabular}{|c|c|c|c|c|c|c|c|c|c|c|c|c|c|c|c|c|}
\hline \multirow[b]{2}{*}{$\begin{array}{l}\text { ROA is the dependent } \\
\text { variable }\end{array}$} & \multicolumn{4}{|c|}{ All firms } & \multicolumn{4}{|c|}{ Large firms } & \multicolumn{4}{|c|}{ Medium firms } & \multicolumn{4}{|c|}{ Small firms } \\
\hline & \multicolumn{2}{|c|}{$\begin{array}{l}\text { One step robust } \\
\text { difference GMM }\end{array}$} & \multicolumn{2}{|c|}{$\begin{array}{l}\text { Twostep robust } \\
\text { difference GMM }\end{array}$} & \multicolumn{2}{|c|}{$\begin{array}{l}\text { One step robust } \\
\text { difference GMM }\end{array}$} & \multicolumn{2}{|c|}{$\begin{array}{l}\text { Twostep robust } \\
\text { difference GMM }\end{array}$} & \multicolumn{2}{|c|}{$\begin{array}{l}\text { One step robust } \\
\text { difference GMM }\end{array}$} & \multicolumn{2}{|c|}{$\begin{array}{l}\text { Twostep robust } \\
\text { difference } \\
\text { GMM }\end{array}$} & \multicolumn{2}{|c|}{$\begin{array}{l}\text { One step } \\
\text { robust } \\
\text { difference } \\
\text { GMM } \\
\end{array}$} & \multicolumn{2}{|c|}{$\begin{array}{c}\text { Twostep } \\
\text { robust } \\
\text { difference } \\
\text { GMM }\end{array}$} \\
\hline \multirow[t]{2}{*}{ Ind Adj Nowc * D } & -0.037 & $* *$ & -0.029 & * & -0.015 & & -0.018 & & -0.031 & & -0.032 & $*$ & -0.042 & & -0.043 & \\
\hline & 0.017 & & 0.016 & & 0.019 & & 0.019 & & 0.019 & & 0.018 & & 0.052 & & 0.046 & \\
\hline \multirow[t]{2}{*}{ Ind Adj Nowc * (1-D) } & 0.110 & $* * *$ & 0.107 & $* * *$ & 0.049 & & 0.013 & & 0.083 & $* * *$ & 0.076 & $* * *$ & 0.201 & $* * *$ & 0.151 & $* *$ \\
\hline & 0.024 & & 0.024 & & 0.044 & & 0.045 & & 0.031 & & 0.029 & & 0.061 & & 0.060 & \\
\hline \multirow[t]{2}{*}{ Sales growth } & 0.014 & $* * *$ & 0.011 & $* *$ & 0.011 & & 0.011 & & 0.017 & $* * *$ & 0.015 & $* * *$ & -0.001 & & 0.003 & \\
\hline & 0.005 & & 0.005 & & 0.007 & & 0.008 & & 0.006 & & 0.006 & & 0.006 & & 0.005 & \\
\hline \multirow[t]{2}{*}{ Leverage } & -0.081 & $* * *$ & -0.082 & $* * *$ & -0.075 & $* * *$ & -0.071 & $* * *$ & -0.078 & $* * *$ & -0.083 & $* * *$ & -0.087 & $* * *$ & -0.077 & $* * *$ \\
\hline & 0.008 & & 0.008 & & 0.015 & & 0.014 & & 0.014 & & 0.014 & & 0.017 & & 0.017 & \\
\hline \multirow[t]{2}{*}{ Size } & -0.041 & $* * *$ & -0.040 & $* * *$ & -0.087 & $* * *$ & -0.073 & $* * *$ & -0.020 & & -0.008 & & -0.039 & $* *$ & -0.024 & \\
\hline & 0.009 & & 0.009 & & 0.014 & & 0.015 & & 0.015 & & 0.015 & & 0.016 & & 0.016 & \\
\hline \multirow[t]{2}{*}{ Fixed assets } & -0.016 & $* *$ & -0.015 & $* *$ & -0.033 & $* * *$ & -0.025 & $* * *$ & -0.006 & & -0.004 & & 0.010 & & 0.003 & \\
\hline & 0.007 & & 0.007 & & 0.008 & & 0.007 & & 0.008 & & 0.008 & & 0.008 & & 0.008 & \\
\hline \multirow[t]{2}{*}{ Age } & -0.006 & $* *$ & -0.007 & $* * *$ & -0.023 & $* * *$ & -0.018 & $* * *$ & 0.001 & & -0.001 & & 0.005 & & 0.004 & \\
\hline & 0.003 & & 0.003 & & 0.007 & & 0.007 & & 0.004 & & 0.004 & & 0.005 & & 0.005 & \\
\hline \multirow[t]{2}{*}{ Sales volatility } & -0.045 & $* * *$ & -0.042 & $* * *$ & -0.051 & $* * *$ & -0.040 & $* * *$ & -0.030 & $* * *$ & -0.025 & $* *$ & -0.047 & $* * *$ & -0.029 & $*$ \\
\hline & 0.007 & & 0.007 & & 0.012 & & 0.012 & & 0.011 & & 0.011 & & 0.017 & & 0.017 & \\
\hline \multirow[t]{2}{*}{ Cash ratio } & 0.097 & $* * *$ & 0.093 & $* * *$ & -0.018 & & -0.006 & & 0.139 & $* * *$ & 0.147 & $* * *$ & 0.109 & $* * *$ & 0.113 & $* * *$ \\
\hline & 0.016 & & 0.015 & & 0.033 & & 0.034 & & 0.022 & & 0.022 & & 0.031 & & 0.030 & \\
\hline \multirow[t]{2}{*}{ Financial distress } & -0.019 & & -0.024 & $*$ & -0.003 & & -0.007 & & -0.020 & & -0.026 & & -0.068 & $* * *$ & -0.037 & $*$ \\
\hline & 0.014 & & 0.013 & & 0.015 & & 0.014 & & 0.015 & & 0.017 & & 0.022 & & 0.020 & \\
\hline Number of observations & 411 & 622 & 411 & 622 & 141 & 346 & 141 & 346 & 186 & 135 & 186,1 & & 84,14 & & 84,1 & \\
\hline
\end{tabular}




\begin{tabular}{|c|c|c|c|c|c|c|c|c|}
\hline $\mathrm{m} 2$ statistics & -0.02 & -0.35 & $1.67 *$ & $1.92 *$ & -0.47 & -0.51 & -1.51 & -0.22 \\
\hline Hansen test & $234.04(92)$ & $234.04(92)$ & $168.04(103)$ & $168.04(103)$ & $178.58(91)$ & $178.58(91)$ & $99.73(92)$ & $99.73(92)$ \\
\hline
\end{tabular}

$* \mathrm{p}<0.1, * * \mathrm{p}<0.05, * * * \mathrm{p}<0.01$.

$\mathrm{m} 2$ is the Arellano-Bond test for autocorrelation of second order asymptotically distributed as a $N(0,1)$ under the null

hypothesis of no serial autocorrelation.

Hansen test is a test of overidentifying restrictions, asymptotically distributed as a chi-squared under the null hypothesis of validity of instruments. Degrees of freedom are indicated under brackets. 
Appendix A Number of observations per country and size

\begin{tabular}{ccccc}
\hline Country & Large & Medium & Small & Total \\
\hline France & 94,398 & 70,056 & 39,036 & 203,490 \\
Germany & 34,685 & 34,196 & 2,992 & 71,873 \\
Italy & 36,313 & 106,113 & 55,260 & 197,686 \\
Total & 165,396 & 210,365 & 97,288 & 473,049 \\
\hline
\end{tabular}


Appendix B Number of observations per industry

\begin{tabular}{|c|c|}
\hline Industry & $\begin{array}{l}\text { Number of } \\
\text { observations }\end{array}$ \\
\hline Agricultural Production - Crops & 1,964 \\
\hline Agricultural Production - Livestock and Animal Specialties & 1,085 \\
\hline Agricultural Services & 1,896 \\
\hline Forestry & 51 \\
\hline Fishing Hunting and Trapping & 142 \\
\hline Metal Mining & 154 \\
\hline Coal Mining & 42 \\
\hline Oil and Gas Extraction & 316 \\
\hline Mining and Quarrying of Nonmetallic Minerals Except Fuels & 1,178 \\
\hline Building Cnstrctn - General Contractors and Operative Builders & 8,484 \\
\hline Heavy Cnstrctn Except Building Construction - Contractors & 5,587 \\
\hline Construction - Special Trade Contractors & 14,002 \\
\hline Food and Kindred Products & 23,219 \\
\hline Tobacco Products & 90 \\
\hline Textile Mill Products & 4,171 \\
\hline Apparel Finished Prdcts from Fabrics and Similar Materials & 3,315 \\
\hline Lumber and Wood Products Except Furniture & 3,084 \\
\hline Furniture and Fixtures & 2,657 \\
\hline Paper and Allied Products & 7,014 \\
\hline Printing Publishing and Allied Industries & 5,909 \\
\hline Chemicals and Allied Products & 13,448 \\
\hline Petroleum Refining and Related Industries & 845 \\
\hline Rubber and Miscellaneous Plastic Products & 10,489 \\
\hline Leather and Leather Products & 1,885 \\
\hline Stone Clay Glass and Concrete Products & 5,891 \\
\hline Primary Metal Industries & 7,489 \\
\hline Fabricated Metal Products Except Machinery and Transport Equipment & 19,777 \\
\hline Industrial and Commercial Machinery and Computer Equipment & 22,650 \\
\hline Electronic Electronical Equipment & 10,197 \\
\hline Transportation Equipment & 6,815 \\
\hline Measure Analyze Control Instruments; Optic Goods; Watchs Clocks & 4,662 \\
\hline Miscellaneous Manufacturing Industries & 2,153 \\
\hline Railroad Transportation & 305 \\
\hline Local Suburban Transit and Interurban Highway Passenger Transport & 4,976 \\
\hline Motor Freight Transportation & 10,623 \\
\hline United States Postal Service & 245 \\
\hline Water Transportation & 2,394 \\
\hline Transportation by Air & 1,104 \\
\hline Pipelines Except Natural Gas & 195 \\
\hline Transportation Services & 9,156 \\
\hline Communications & 2,275 \\
\hline Electric Gas and Sanitary Services & 17,170 \\
\hline Wholesale Trade - Durable Goods & 79,652 \\
\hline
\end{tabular}


Wholesale Trade - Nondurable Goods

Building Materials Hardware Garden Supply and Mobile Home

Dealers

General Merchandise Stores

Food Stores

18,839

Automotive Dealers and Gasoline Service Stations

2,812

Apparel and Accessory Stores

3,644

Home Furniture Furnishings and Equipment Stores

2,834

Eating and Drinking Places

2,137

Miscellanous retail

Hotels Rooming Houses Camps and Other Lodging Places

2,920

Personal Services

1,638

Business Services

Automotive Repair Services and Parking

Miscellaneous Repair Services

Motion Pictures

1,697

Amusement and Recreation Services

Health Services

Legal Services

Educational Services

Social Services

Museums Art Galleries and Botanical and Zoological Gardens

Engineering Accounting Research Management and Related Services 